\title{
AVALIAÇÃO FÍSICO-QUÍMICA DE EFLUENTE GERADO EM BIODIGESTOR ANAERÓBIO PARA FINS DE AVALIAÇÃO DE EFICIÊNCIA E APLICAÇÃO COMO FERTILIZANTE AGRÍCOLA
}

\author{
Wilson Tadeu Lopes da Silva* e Antonio Pereira de Novaes ${ }^{\dagger}$ \\ Embrapa Instrumentação, Rua XV de Novembro, 1452, 13560-970 São Carlos - SP, Brasil \\ Vivian Kuroki \\ Embrapa Instrumentação, Rua XV de Novembro, 1452, 13560-970 São Carlos - SP / Departamento de Química, Universidade \\ Federal de São Carlos, CP 676, 13560-970 São Carlos - SP, Brasil \\ Lilian Fernanda de Almeida Martelli \\ Embrapa Instrumentação, Rua XV de Novembro, 1452, 13560-970 São Carlos - SP / Instituto de Química de São Carlos, \\ Universidade de São Paulo, CP 780, 13560-970 São Carlos - SP, Brasil \\ Lourenço Magnoni Júnior \\ Escola Técnica Estadual Astor de Mattos Carvalho, Centro Estadual de Educação Tecnológica Paula Souza, Zona Rural, s/n, \\ 17480-000 Cabrália Paulista - SP, Brasil
}

Recebido em 20/12/10; aceito em 6/6/11; publicado na web em 22/7/11

\begin{abstract}
PHYSICO-CHEMICAL EVALUATION OF AN EFFLUENT TREATED IN ANAEROBIC BIODIGESTER REGARDING ITS EFFICIENCE AND APPLICATION AS FERTILIZER. The use of biodigester for basic and environmental sanitation has large demand in Brazil. A biodigester was built to treat conjunctly the human and pig feces and urine, regarding to its future application in rural small towns. The results show that the biodigester can reduce $90 \%$ of COD and BOD and, up to $99.99 \%$ of thermotolerant coliforms. The treated effluent has variable quantities of macro- and micro-nutrients; and organic matter. However, the concentration variability of the nutrients makes difficult a dosed application into soil. The soluble salts (mainly as $\mathrm{Na}^{+}$form) make necessary a controlled use to avoid environmental degradation.
\end{abstract}

Keywords: anaerobic biodigester; sewage treatment; fertilizer.

\section{INTRODUÇÃO}

A biodigestão anaeróbia é um processo microbiológico onde uma série de micro-organismos, na ausência de ar, atuam na transformação da matéria orgânica (MO) lábil, passando de moléculas mais complexas para aquelas com estruturas mais simples. Como resultado da biodigestão anaeróbia de excrementos, têm-se a produção de biogás e um efluente clarificado e mais estabilizado química e microbiologicamente. Digestores têm demonstrado consideráveis benefícios sócio-econômicos em todo o mundo. Os Estados Unidos e o Canadá têm colocado especial ênfase na pesquisa e desenvolvimento de biodigestores anaeróbios, tal qual ocorre em países emergentes como a China e a Índia, que possuem programas extensos para implementar biodigestores. ${ }^{1,2}$

A China é o segundo maior consumidor de energia do mundo e é responsável por boa parte da liberação dos gases do efeito estufa para a atmosfera e, assim, tem investido pesadamente em projetos de proteção ambiental e na geração de energia renovável. Com a adoção desta política, o governo chinês tem estimulado substancialmente pesquisas através da construção, operação e eficiência de biodigestores. ${ }^{3,4}$

No Brasil, estudos envolvendo o uso de biodigestores têm sido utilizados em duas principais vertentes: tratamento de efluentes e uso energético do biogás. Existe uma terceira vertente importante relacionada ao uso do efluente para melhorar a fertilidade de solo e, com isso, aumentar a sustentabilidade do sistema produtivo. ${ }^{5}$

Sistemas biodigestores, ainda no país, são apresentados na literatura visando o tratamento de resíduos de processamento de

*e-mail: wilson@cnpdia.embrapa.br

†n Memoriam mandioca, ${ }^{6}$ estercos bovino e suíno, ${ }^{7,8}$ com excelentes resultados do ponto de vista sanitário e ambiental.

O uso de um sistema biodigestor no tratamento de esgoto residencial rural foi desenvolvido na Embrapa Instrumentação, apresentando excelentes resultados tanto do ponto de vista sanitário, quanto do uso do efluente na agricultura. ${ }^{9}{ }^{10}$ Segundo a FAO-ONU (Food Agricultural Organization - Organização das Nações Unidas), a agricultura de base familiar reúne 14 milhões de pessoas, mais de $60 \%$ do total de agricultores, e detém $75 \%$ dos estabelecimentos agrícolas no Brasil. É comum nessas propriedades o uso de fossas rudimentares (fossa "negra", fosso, buraco, etc.), que acabam por contaminar águas subterrâneas e, consequentemente, os poços de água abastecidos por lençóis freáticos, os conhecidos poços "caipiras". ${ }^{11}$

Outra fonte importante de contaminação ambiental e para a saúde pública, refere-se ao descarte de resíduos oriundos da criação animal em confinamentos. Segundo pesquisa pecuária municipal realizada pelo IBGE - Instituto Brasileiro de Geografia e Estatística, ${ }^{12}$ o Brasil possui aproximadamente 38 milhões de cabeças de suínos, a grande maioria em confinamento. Para fins de comparação, um suíno defeca, em média, quantidade equivalente a dejetos de 5 pessoas; portanto, um confinamento de 1000 animais gera resíduos equivalentes ao de uma cidade pequena, de forma bastante concentrada.

Alia-se a tudo isso o problema da escassez de água, que é agravada em virtude da falta de manejo e usos sustentáveis dos recursos naturais. Dentro dessa ótica, os esgotos tratados têm um papel fundamental no planejamento e na gestão sustentável dos recursos hídricos como um substituto para o uso de águas destinadas a fins agrícolas e de irrigação. $\mathrm{O}$ uso de biodigestores anaeróbios possibilita esta visão, pois é bastante eficiente, desde que seja bem manuseado.

Os trabalhos científicos sobre a utilização de esgotos tratados em práticas agrícolas têm demonstrado que sua disposição no solo adi- 
ciona uma série de substâncias que podem alterar suas propriedades físicas, químicas e biológicas, afetando, em geral, o desenvolvimento das plantas. ${ }^{13-18}$ Os resíduos de esgotos gerados após tratamento são constituídos essencialmente de água com a presença de minerais e MO suspensa ou dissolvida. Entretanto, em alguns casos, a quantidade relativamente grande de nutrientes, como fosfatos, nitratos e amônio, favorece a eutrofização de corpos de água, comprometendo a qualidade das águas superficiais e limitando a disposição do efluente tratado no local. ${ }^{19}$ A principal vantagem da utilização de efluentes na agricultura reside na recuperação de um recurso de grande importância para a agricultura - a água; além disso, os constituintes desses efluentes são produtos que podem aumentar a fertilidade dos solos por conterem nutrientes essenciais às plantas, em virtude da MO que lhe é adicionada, com a consequente formação de húmus. ${ }^{20}$

Em vista desses fatos, foi instalado um biodigestor anaeróbio na Escola Técnica Estadual (ETEC) Astor de Mattos Carvalho, do Centro Estadual de Educação Tecnológica Paula Souza (CEETEPS), na cidade de Cabrália Paulista, SP. Com esse sistema, os dejetos de suínos criados no local e dejetos humanos são tratados conjuntamente. Os objetivos desse trabalho foram acompanhar o processo de biodigestão através de determinações físico-químicas e microbiológicas do efluente (CONAMA 357) e caracterizar o efluente gerado, em termos de quantidade de nutrientes e matéria orgânica, visando futura aplicação agronômica.

\section{PARTE EXPERIMENTAL}

O biodigestor utilizado (Figura 1), foi instalado na ETEC Astor de Mattos Carvalho, na cidade de Cabrália Paulista/SP (22²8'43" $\mathrm{S}$ e $\left.49^{\circ} 19^{\prime} 10^{\prime \prime} \mathrm{O}\right)$ e representa um sistema de médio porte do tipo tubular (também conhecido como biodigestor canadense), com capacidade para armazenar aproximadamente $250 \mathrm{~m}^{3}$ de líquidos em seu interior. As dimensões do biodigestor são $50,5 \mathrm{~m}$ de comprimento, 1,8 $\mathrm{m}$ de profundidade, 4,5 $\mathrm{m}$ de largura (superior) e 1,0 $\mathrm{m}$ (inferior) com um corte transversal em formato de trapézio regular. Foi utilizada geomembrana de EPDM (borracha de etileno-propileno-dieno) fornecida pela Firestone Building Products. Na saída do biodigestor existe uma caixa de coleta do efluente tratado com capacidade para receber $25 \mathrm{~m}^{3}$ de líquido.

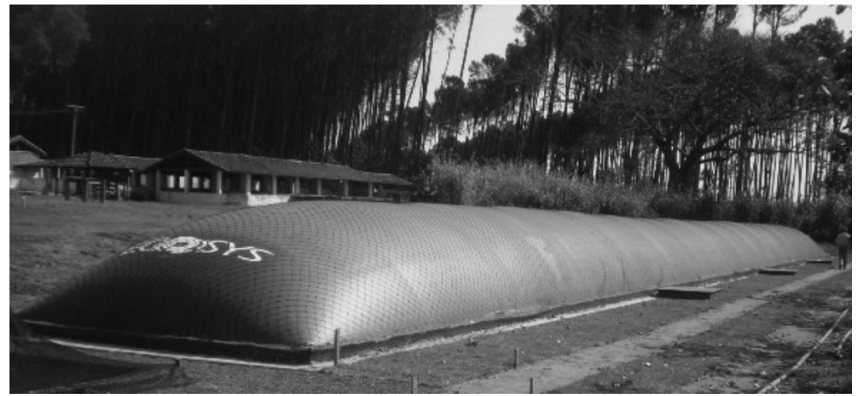

Figura 1. Biodigestor piloto instalado em Cabrália Paulista, SP

Durante o experimento, o biodigestor recebia um volume diário que variava de 8 a $10 \mathrm{~m}^{3}$, indicando um tempo mínimo de retenção hídrica de 25 dias. $\mathrm{O}$ afluente era composto pelo esgoto gerado por 100 alunos (somente vaso sanitário), morando em semi-internato, bem como a água proveniente da área de confinamento $\left(280 \mathrm{~m}^{2}\right)$ que continha 50 suínos em fase de crescimento e terminação, a qual era lavada 2 vezes ao dia. A composição volumétrica do afluente era em média $50 \%$ humano e $50 \%$ suíno. O biodigestor não recebia água de chuva.

O sistema biodigestor possui 5 pontos onde são feitas as coletas do efluente para realização de suas análises. Estes pontos estão representados na Figura 2, sendo o ponto 1 correspondente ao afluente, os pontos 2,3 e 4 ao efluente em processo de tratamento anaeróbio e o ponto 5 ao efluente já tratado. O ponto 5 foi dividido em duas amostragens: $5 \mathrm{a}$ - tubo de saída do efluente do biodigestor e, $5 \mathrm{~b}$ tanque receptor. Para a realização dos ensaios em laboratório, foram coletadas amostras nos pontos 1 e 5 . As amostragens ocorreram em diferentes períodos nos anos de 2008 e 2009.

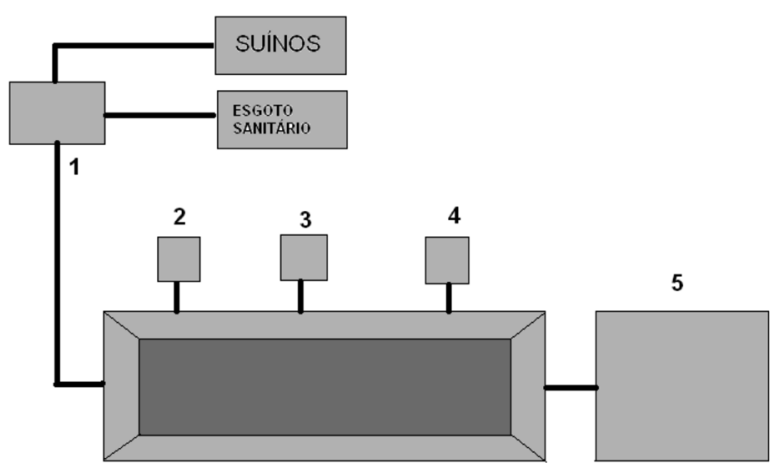

Figura 2. Esquema do biodigestor e de seus cinco pontos de coleta

Durante as coletas bimestrais de outubro de 2008 a outubro de 2009, foram determinados valores de $\mathrm{pH}$, oxigênio dissolvido, potencial redox, condutividade e temperatura utilizando-se uma sonda multiparâmetros WTW modelo Multi340i. As amostras levadas ao laboratório foram armazenadas em frascos separados de vidro âmbar, limpos e esterilizados. As amostras coletadas foram colocadas sob refrigeração imediatamente após a coleta e assim transportadas. Para as amostras a serem analisadas por ICP-OES (espectrometria de emissão ótica com plasma acoplado indutivamente), antes da refrigeração, as amostras foram acidificadas com $\mathrm{HCl}$ até $\mathrm{pH}$ 1,0.

No que se refere à fertilidade, o efluente foi caracterizado em termos de quantidade de macro e micronutrientes, bem como a matéria orgânica presente. Para tais ensaios, as amostras foram analisadas via ICP-OES, nos laboratórios da Embrapa Pecuária Sudeste, com exceção do nitrogênio, que foi determinado através do método Kjedhal, no Laboratório de Saneamento da Universidade de São Paulo, juntamente com outros parâmetros relevantes de serem comparados com a Resolução $n^{\circ} 357$ do CONAMA (Conselho Nacional do Meio Ambiente). As análises bacteriológicas foram iniciadas em um período máximo de 24 h após a coleta. Os ensaios foram efetuados de acordo com a $21^{\mathrm{a}}$ edição do Standard Methods. ${ }^{21}$

Investigou-se através da espectroscopia de absorbância na região do infravermelho (FTIR) a qualidade da matéria orgânica presente no efluente tratado. Utilizou-se um espectrofotômetro de FTIR Perkin Elmer, Paragon 1000 PC. Os espectros de pastilhas das amostras sólidas do efluente liofilizado, preparadas com 1,0 mg de amostra e $100 \mathrm{mg}$ de $\mathrm{KBr}$, foram obtidos a partir de 64 varreduras, com resolução espectral de $4 \mathrm{~cm}^{-1}$.

Utilizou-se também a espectroscopia de absorbância na região do ultravioleta e do visível (UV/Vis) como método de avaliação da matéria orgânica. A partir dos espectros, foi determinada a razão $\mathrm{E}_{4} /$ $\mathrm{E}_{6}$ (razão entre as absorbâncias obtidas em 465 e 665 nm, respectivamente $)^{22}$ utilizada em análises de substâncias húmicas e matéria orgânica de solos e águas. Foram diluídos $10 \mathrm{~mL}$ de efluente em um balão de $50 \mathrm{~mL}$ de solução $0,05 \mathrm{~mol} \mathrm{~L}^{-1}$ de $\mathrm{NaHCO}_{3}$. Foram feitas varreduras dos espectros nas regiões ultravioleta e visível ( 800 a 200 $\mathrm{nm}$ ). Os espectros foram obtidos através de um espectrofotômetro Shimadzu UV-1601PC. 


\section{RESULTADOS E DISCUSSÃO}

\section{Análises in situ}

Os resultados das análises físico-químicas determinadas in situ são apresentados nas Tabelas 1 a 5. Durante o período, observou-se que a variação de temperatura nos momentos de coleta foi de 20,0 a $31,0^{\circ} \mathrm{C}$, sendo as temperaturas bastante similares entre os diferentes pontos de amostragem do sistema. $\mathrm{O}$ pH em cada ponto de coleta manteve-se na faixa de aproximadamente 7 , sendo esse valor propício ao crescimento de micro-organismos que degradam a matéria orgânica na ausência de oxigênio. Os resultados de oxigênio dissolvido (geralmente menores que $1 \mathrm{mg} \mathrm{L}^{-1}$ ) e potencial redox $(\leq 0 \mathrm{mV})$ apresentam-se dentro do esperado para um sistema anaeróbio. Os valores da condutividade elétrica foram aqueles que mais variaram nas diferentes análises, com valor mínimo de 2,06 até máximo de $4,87 \mathrm{mS} \mathrm{cm}^{-1}$, e um aumento pronunciado no mês de agosto de 2009 . A condutividade elétrica confere certo grau de salinidade presente no efluente, podendo este ser classificado por este parâmetro como "água salobra", o que limita sua utilização em irrigação agrícola, mas não o seu uso como fertilizante, desde que controlado. ${ }^{23,24}$ Com exceção da temperatura, não foram observadas variações nos parâmetros em função do período do ano.

Um resultado representativo das análises microbiológicas e físico-químicas do afluente e do efluente é apresentado na Tabela 6.
Obteve-se uma redução bastante expressiva quanto às taxas de DQO e DBO de aproximadamente 97 e $96 \%$, respectivamente, assim como o $E$. coli que apresentou uma redução de 99,9999\% muito significante do ponto de vista de redução de patógenos, porém ainda não alcançando um valor absoluto adequado para lançamento direto em corpos d'água. ${ }^{25}$ A proposta de utilizar o efluente no solo como componente para fertirrigação, proporciona um tratamento terciário do efluente, pela capacidade depurante que o solo possui ${ }^{26}$ Os pontos 5 a e $5 b$ podem diferir discretamente em alguns parâmetros, principalmente sólidos suspensos, provavelmente devido ao crescimento de algumas algas e poeira no tanque de armazenamento.

Os elementos de interesse avaliados levaram em conta o potencial fertilizante e alguns elementos potencialmente danosos ao ambiente ( $\mathrm{Na}, \mathrm{Al}$ e $\mathrm{Ba}$ ). Não foram encontradas variações que poderiam ser consideradas como sazonais (valores não apresentados), dentro do período de amostragem (junho/2008 a março de 2009). A Tabela 7 apresenta as concentrações médias dos elementos, bem como os valores máximos e mínimos encontrados. O elemento nutritivo mais abundante é o nitrogênio, na forma amoniacal, com quantidades apreciáveis de potássio, cálcio, fósforo e magnésio. Estes elementos se apresentam em forma solúvel, o que influencia sua mobilidade no solo, fato que deve ser levado em conta para evitar contaminação de águas subterrâneas. Esta mobilidade dependerá de fatores como características de capacidade de troca de cátions do solo, $\mathrm{pH}$, capacidade de absorção pela biota, entre outros. Estes elementos podem

Tabela 1. Temperatura $\left({ }^{\circ} \mathrm{C}\right)$ da solução nos diferentes pontos de amostragem e em diferentes períodos do ano

\begin{tabular}{|c|c|c|c|c|c|c|c|c|}
\hline \multicolumn{9}{|c|}{ Momento da amostragem } \\
\hline Ponto de coleta & Out/08 & Dez/08 & Fev/09 & Abr/09 & Jun/09 & Ago/09 & Out/09 & Média \\
\hline 1 & 31,0 & 27,0 & 26,8 & 29,1 & 20,0 & 21,2 & 25,2 & $25,8 \pm 4,0$ \\
\hline 2 & 30,0 & 26,3 & 28,7 & 26,0 & 20,6 & 24,1 & 25,3 & $25,9 \pm 3,1$ \\
\hline 3 & 30,0 & 26,1 & 28,3 & 25,9 & 20,4 & 23,9 & 24,8 & $25,6 \pm 3,1$ \\
\hline 4 & 29,5 & 26,0 & 29,0 & 25,6 & 20,2 & 23,7 & 26,3 & $25,8 \pm 3,2$ \\
\hline $5 \mathrm{a}$ & 28,3 & - & 27,8 & 26,1 & 21,3 & 26,9 & 25,2 & $22,2 \pm 2,5$ \\
\hline $5 b$ & 30,5 & 24,4 & 28,2 & 27,2 & 21,0 & 23,1 & 24,6 & $25,6 \pm 3,2$ \\
\hline
\end{tabular}

Tabela 2. Valores de $\mathrm{pH}$ da solução nos diferentes pontos de amostragem e em diferentes períodos do ano

\begin{tabular}{|c|c|c|c|c|c|c|c|c|}
\hline \multicolumn{9}{|c|}{ Momento da amostragem } \\
\hline Ponto de coleta & Out/08 & Dez/08 & Fev/09 & Abr/09 & Jun/09 & Ago/09 & Out/09 & Média \\
\hline 1 & 7,1 & 6,3 & 6,1 & 6,2 & 6,8 & 7,1 & 5,9 & $6,5 \pm 0,5$ \\
\hline 2 & 7,0 & 6,8 & 6,7 & 6,8 & 6,8 & 6,8 & 6,7 & $6,8 \pm 0,1$ \\
\hline 3 & 7,0 & 6,8 & 6,7 & 6,8 & 6,8 & 6,8 & 6,7 & $6,8 \pm 0,1$ \\
\hline 4 & 7,0 & 6,8 & 6,7 & 6,8 & 6,8 & 6,8 & 6,7 & $6,8 \pm 0,1$ \\
\hline $5 \mathrm{a}$ & 7,0 & - & 6,9 & 6,9 & 7,0 & 6,8 & 6,8 & $6,9 \pm 0,1$ \\
\hline $5 b$ & 7,2 & 7,3 & 7,1 & 7,2 & 6,9 & 7,1 & 7,2 & $7,1 \pm 0,1$ \\
\hline
\end{tabular}

Tabela 3. Oxigênio dissolvido $\left(\mathrm{mg} \mathrm{L}^{-1}\right)$ da solução nos diferentes pontos de amostragem e em diferentes períodos do ano

\begin{tabular}{|c|c|c|c|c|c|c|c|c|}
\hline \multicolumn{9}{|c|}{ Momento da amostragem } \\
\hline Ponto de coleta & Out/08 & Dez/08 & Fev/09 & Abr/09 & Jun/09 & Ago/09 & Out/09 & Média \\
\hline 1 & 0,29 & 0,08 & 0,70 & 0,30 & 0,33 & 0,40 & 0,68 & $0,40 \pm 0,22$ \\
\hline 2 & 0,30 & 0,05 & 0,63 & 0,56 & 0,68 & 0,11 & 0,44 & $0,40 \pm 0,25$ \\
\hline 3 & 0,15 & 0,06 & 0,30 & 0,50 & 0,84 & 0,07 & 0,35 & $0,32 \pm 0,28$ \\
\hline 4 & 0,30 & 0,05 & 0,70 & 0,50 & 0,50 & 0,09 & 0,30 & $0,35 \pm 0,23$ \\
\hline $5 \mathrm{a}$ & 0,30 & - & 0,53 & 0,50 & 0,60 & 0,08 & 0,30 & $0,39 \pm 0,19$ \\
\hline $5 b$ & 0,27 & 0,15 & 1,13 & 1,08 & 0,68 & 0,13 & 0,90 & $0,62 \pm 0,44$ \\
\hline
\end{tabular}


Tabela 4. Potencial redox $(\mathrm{mV})$ da solução nos diferentes pontos de amostragem e em diferentes períodos do ano

\begin{tabular}{ccccccccc}
\hline & \multicolumn{9}{c}{ Momento da amostragem } & & \\
Ponto de coleta & Out/08 & Dez/08 & Fev/09 & Abr/09 & Jun/09 & Ago/09 & Out/09 & Média \\
\hline 1 & -11 & 23 & 34 & 26 & -2 & -24 & -48 & $13,43 \pm 26,15$ \\
2 & 0 & -6 & -1 & -8 & -4 & -8 & -2 & $-4,14 \pm 3,29$ \\
3 & 0 & -9 & 0 & -8 & -3 & -7 & -2 & $-4,14 \pm 3,80$ \\
4 & 0 & -9 & -2 & -7 & -4 & -9 & -3 & $-4,86 \pm 3,53$ \\
$5 \mathrm{a}$ & 0 & - & -12 & -12 & -13 & -5 & -6 & $-8,00 \pm 5,18$ \\
$5 \mathrm{~b}$ & -10 & -37 & -25 & -2 & -13 & -25 & -34 & $-20,86 \pm 12,93$ \\
\hline
\end{tabular}

Tabela 5. Condutividade elétrica $\left(\mathrm{mS} \mathrm{cm}^{-1}\right)$ da solução nos diferentes pontos de amostragem e em diferentes períodos do ano

\begin{tabular}{ccccccccc}
\hline & \multicolumn{9}{c}{ Momento da amostragem } & & & \\
Ponto de coleta & Out/08 & Dez/08 & Fev/09 & Abr/09 & Jun/09 & Ago/09 & Out/09 & Média \\
\hline 1 & 3,24 & 2,12 & 3,97 & 2,06 & 2,24 & 2,55 & 2,59 & $2,68 \pm 0,69$ \\
2 & 3,60 & 4,46 & 2,87 & 3,68 & 3,34 & 4,84 & 2,46 & $3,61 \pm 0,83$ \\
3 & 3,68 & 4,52 & 2,88 & 3,76 & 3,78 & 4,81 & 2,53 & $3,71 \pm 0,81$ \\
4 & 3,58 & 4,47 & 2,83 & 3,65 & 3,77 & 4,87 & 2,53 & $3,67 \pm 0,83$ \\
$5 \mathrm{a}$ & 3,63 & - & 2,89 & 3,64 & 3,76 & 4,52 & 2,50 & $3,49 \pm 0,71$ \\
$5 \mathrm{~b}$ & 3,58 & 4,23 & 2,91 & 3,62 & 3,74 & 4,63 & 2,62 & $3,62 \pm 0,70$ \\
\hline
\end{tabular}

Tabela 6. Resultado representativo das análises físico-químicas e microbiológicas do efluente na entrada e saída do biodigestor (análise realizada em 19/11/2008)

\begin{tabular}{lccc}
\hline & Ponto 1 & Ponto 5a & Ponto 5b \\
\hline $\mathrm{pH}$ & 6,0 & 7,0 & 7,3 \\
Demanda química de oxigênio $\left(\mathrm{mg} \mathrm{O}_{2} \mathrm{~L}^{-1}\right)$ & 13160 & 366 & 296 \\
Demanda bioquímica de oxigênio $\left(\mathrm{mg} \mathrm{O}_{2} \mathrm{~L}^{-1}\right)$ & 8594 & 209 & 186 \\
Nitrogênio nitrato $\left(\mathrm{mg} \mathrm{L}^{-1}\right)$ & 19,17 & 1,63 & 1,65 \\
Nitrogênio nitrito $\left(\mathrm{mg} \mathrm{L}^{-1}\right)$ & $<0,001$ & $<0,001$ & $<0,001$ \\
Nitrogênio amoniacal $\left(\mathrm{mg} \mathrm{L}^{-1}\right)$ & 337 & 443 & 402 \\
Nitrogênio Kjeldhal $\left(\mathrm{mg} \mathrm{L}^{-1}\right)$ & 1067 & 619 & 694 \\
Fosfato total (mg L-1) & 208 & 83 & 61 \\
Óleos e graxas (mg L-1) & 394 & 72 & 76 \\
Coliformes totais $\left(\mathrm{UFC}^{*} / 100 \mathrm{~mL}^{-1}\right)$ & $5,710^{12}$ & $4,710^{8}$ & $2,310^{8}$ \\
E. coli $\left(\mathrm{UFC} * 100 \mathrm{~mL}^{*}\right)$ & $2,110^{10}$ & $1,010^{6}$ & $2,010^{5}$ \\
Sólidos sedimentáveis $\left(\mathrm{mg} \mathrm{L}^{-1}\right)$ & 120,0 & 0,7 & 7,0 \\
Sólidos suspensos totais $\left(\mathrm{mg} \mathrm{L}^{-1}\right)$ & 8335 & 144 & 214 \\
Sólidos suspensos fixos $\left(\mathrm{mg} \mathrm{L}^{-1}\right)$ & 1968 & 16 & 98 \\
Sólidos suspensos voláteis $\left(\mathrm{mg} \mathrm{L}^{-1}\right)$ & 6367 & 128 & 116 \\
\hline
\end{tabular}

* Unidade Formadora de Colônia

ser também ser facilmente lixiviáveis na superfície, caso ocorra excesso de aplicação.

Pelos resultados apresentados, pode-se observar que os valores de concentração dos elementos variam significativamente, podendo o valor máximo para alguns elementos ser superior ao dobro do valor mínimo. Este fato dificulta a aplicação do efluente como fertilizante, já que torna difícil uma dosagem precisa do elemento nutriente. Outro ponto que deve ser destacado é a presença de sódio em concentração que merece atenção. $\mathrm{O}$ uso intensivo de águas contendo grande quantidade de sódio pode levar à salinização do solo, onde coloides
Tabela 7. Elementos de interesse presentes no efluente tratado (ponto 5). Os valores correspondem a 5 coletas diferentes ocorridas entre junho de 2008 e março de 2009

\begin{tabular}{cccc}
\hline Elemento & \multicolumn{3}{c}{ Valores $\left(\mathrm{mg} \mathrm{L}^{-1}\right)$} \\
Média & 226 & Máximo \\
\hline $\mathrm{N}$ & 298 & 38,6 & 390 \\
$\mathrm{P}$ & 50,60 & 90,53 & 70,96 \\
$\mathrm{~K}$ & 116,64 & 62,95 & 164,20 \\
$\mathrm{Ca}$ & 76,11 & 24,75 & 97,86 \\
$\mathrm{Mg}$ & 29,63 & 2,46 & 37,58 \\
$\mathrm{~S}$ & 3,78 & 0,03 & 5,51 \\
$\mathrm{Cu}$ & 0,08 & 0,48 & 0,14 \\
$\mathrm{Fe}$ & 1,01 & 0,26 & 1,67 \\
$\mathrm{Mn}$ & 0,32 & 0,11 & 0,40 \\
$\mathrm{Zn}$ & 0,22 & 0,31 & 0,36 \\
$\mathrm{Sr}$ & 0,43 & 0,01 & 0,61 \\
$\mathrm{~V}$ & 0,10 & 81,30 & 0,24 \\
$\mathrm{Na}$ & 117,06 & 0,05 & 161,67 \\
$\mathrm{Ba}$ & 0,30 & 0,35 & 0,85 \\
$\mathrm{Al}$ & 0,54 & 0,78 \\
\hline
\end{tabular}

*Nitrogênio determinado por método Kjeldhal. Outros elementos por ICP-OES.

orgânicos e inorgânicos podem ser desestabilizados, diminuindo a fertilidade desse. ${ }^{27}$ A presença de concentrações significativas de sais de potássio pode também ser danosa, entretanto, seu efeito no solo é minimizado por ser um nutriente facilmente absorvido pelas plantas. Fica claro que o uso do efluente tratado pelo biodigestor deve ser utilizado de forma controlada, para que se evite algum tipo de impacto negativo no solo.

A matéria orgânica presente no efluente também foi analisada, para se compreender um pouco melhor as modificações estruturais que podem ocorrer após sua aplicação no solo. Foram utilizadas as 
espectroscopias de absorbância na região do UV/Vis e a de infravermelho com transformada de Fourier (FTIR).

Os espectros da matéria orgânica do efluente na região do UV/ Vis apresentaram decréscimo na absorção com o aumento do comprimento de onda, sem bandas pronunciadas, conforme apresentado na Figura 3. Para fins comparativos considerou-se a razão entre as absorbâncias em 465 e 665 nm, conhecida como $\mathrm{E}_{4} / \mathrm{E}_{6}$, muito utilizadas em estudos de substâncias húmicas. Os valores obtidos (Tabela 8) são similares àqueles encontrados para ácidos húmicos extraídos de solos. ${ }^{22}$ Quanto menor o valor de $\mathrm{E}_{4} / \mathrm{E}_{6}$, maior será a colaboração relativa da absorbância em maiores comprimentos de onda e, portanto, maior a complexidade do sistema eletrônico conjugado. Observa-se um pequeno aumento da razão $\mathrm{E}_{4} / \mathrm{E}_{6}$ da matéria orgânica que sai do biodigestor, comparada com a que entra. Isto significa que o material orgânico presente no efluente tratado apresenta características estruturais mais simples que o material de entrada, sendo coerente com o que se espera de um sistema de tratamento, onde estruturas mais complexas, como proteínas, por exemplo, são degradadas.

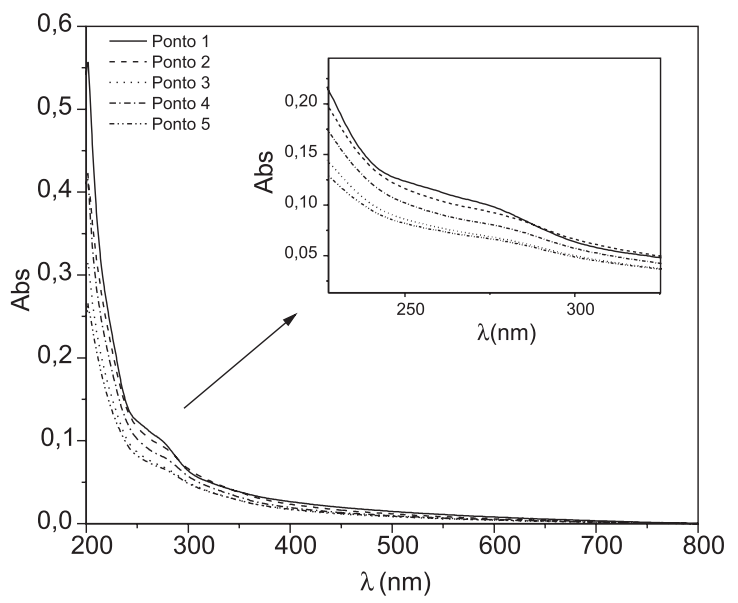

Figura 3. Espectros de absorção de luz UV-visível de efluente. Coleta em $29 / 7 / 08$

Tabela 8. Valores das razões $\mathrm{E}_{4} / \mathrm{E}_{6}$ dos efluentes em dois períodos diferentes do ano de 2008

\begin{tabular}{lcc}
\hline Coleta & & Razão $\mathrm{E}_{4} / \mathrm{E}_{6}$ \\
\hline $29 / 07 / 08$ & Ponto 1 & 3,65 \\
& Ponto 5 & 4,25 \\
\hline $15 / 10 / 08$ & Ponto 1 & 4,30 \\
& Ponto 5 & 5,60 \\
\hline
\end{tabular}

Os espectros de FTIR da matéria orgânica do efluente são apresentados na Figura 4 (A e B). Observa-se uma banda centrada em torno de $3270 \mathrm{~cm}^{-1}$, que é atribuída ao estiramento O-H e N-H. As bandas centradas em $2900 \mathrm{~cm}^{-1}$ representam estiramentos $\mathrm{C}-\mathrm{H}$ de $\mathrm{CH}_{2}$ e $\mathrm{CH}_{3}$. Estas funções químicas geralmente estão associadas a estruturas alifáticas presentes na matéria orgânica. A diminuição das bandas destas regiões, após o tratamento anaeróbio, é um indício de que estas estruturas são degradadas microbiologicamente ou decantam com o lodo remanescente do processo. Uma banda centrada em $1660 \mathrm{~cm}^{-1}$ pode ser atribuída ao estiramento $\mathrm{C}=\mathrm{O}$ de grupos carbonílicos. Também foi observada uma banda em $1624 \mathrm{~cm}^{-1}$, atribuída ao estiramento de íons $\mathrm{COO}^{-}$(coordenados ou não a metais). Outra banda, em 1400 $\mathrm{cm}^{-1}$, é atribuída aos estiramentos $v\left(\mathrm{COO}^{-}\right)$de grupos carboxilatos, sendo estes resultados coerentes com o caráter $\mathrm{pH}$-neutro do efluente. Na região de 1100 a $1000 \mathrm{~cm}^{-1}$ observaram-se bandas provenientes do estiramento $\mathrm{C}-\mathrm{O}$ de polissacarídeos. A forte intensidade nessa região é praticamente constante nas amostras durante todo o processo de biodigestão, em virtude de muitos polissacarídeos apresentarem alta resistência à degradação biológica. A região entre $800 \mathrm{a} 400 \mathrm{~cm}^{-1}$ é de difícil identificação, geralmente atribuída a compostos aromáticos e absorção de compostos silicatados. ${ }^{19}$

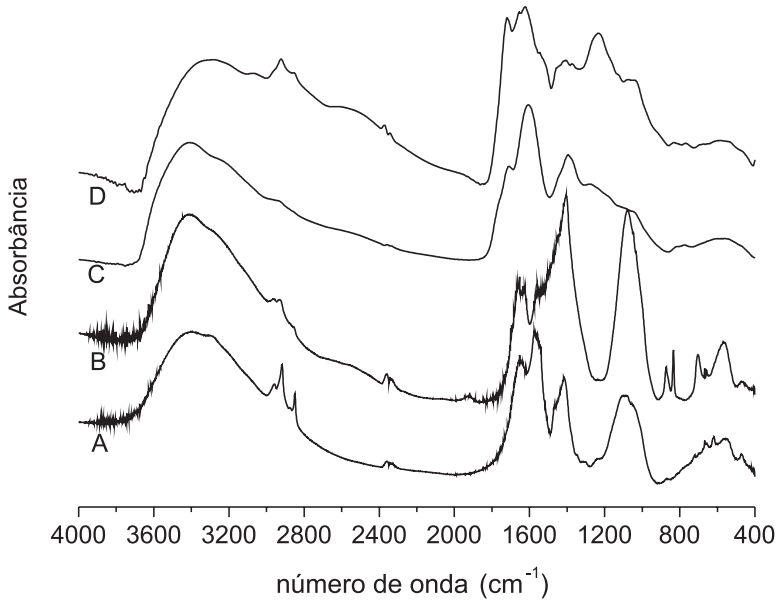

Figura 4. Espectros de infravermelho com transformada de Fourier (FTIR) da matéria orgânica coletada no ponto 1 (A) e no ponto 5 (B) em comparação com substâncias húmicas aquática $(C)$ e terrestre $(D)$. Amostragem do efluente em novembro/2008

Para fins de comparação, são apresentados espectros de substâncias húmicas (representativas de matéria orgânica mais estável) aquática e terrestre (figura $4 \mathrm{C}$ e $4 \mathrm{D}$, respectivamente). Observa-se uma diferença clara na região próxima a $1100 \mathrm{~cm}^{-1}$, característica da presença de derivados de polissacarídeos, bastante pronunciada no material orgânico do efluente, mas muito discreta nas substâncias húmicas. A região em torno de $1200 \mathrm{~cm}^{-1}$ é representativa de estruturas aromáticas, sendo pouco pronunciada no material proveniente do biodigestor. A região representativa das funções ácido carboxílico/carboxilato (1700 a $1500 \mathrm{~cm}^{-1}$ ) é também melhor definida nas $\mathrm{SH}$. Por tudo isso, pode-se definir que a MO presente no efluente se apresenta ainda em processo de biodegradação, diferentemente da MO recalcitrante presente no solo e água. Quando em contato com o solo, o material orgânico proveniente do efluente será ainda transformado microbiologicamente, podendo ser mineralizado a $\mathrm{CO}_{2}$ e/ou incorporado ao húmus. ${ }^{22}$

\section{CONCLUSÕES}

Pelos resultados apresentados, pode-se concluir que o biodigestor utilizado no tratamento conjunto de resíduos humanos e suínos é perfeitamente viável nas condições estabelecidas, com níveis de diminuição de DBO, DQO e coliformes bastante interessantes, entretanto, o efluente tratado não pode ser descartado diretamente em corpos d'água, sem uma depuração prévia.

O efluente tratado possui características muito interessantes em termos de fertilidade. A confirmação pode ser observada pela presença de vários elementos solúveis que são nutrientes para plantas, com ênfase no nitrogênio na forma amoniacal e no fósforo, além de uma série de micronutrientes. A matéria orgânica solúvel ou em suspensão, durante a sua degradação, possibilitará também a liberação dos nutrientes presentes na sua constituição. Quantidades variáveis dos elementos, nas diferentes coletas, mostram a dificuldade de uma aplicação exata dos nutrientes. Outro fator a se levar em conta são os níveis relativamente altos de sódio e condutividade elétrica, tornando 
necessário que o líquido tratado seja utilizado de forma controlada e não indiscriminadamente em uma irrigação.

A matéria orgânica presente no efluente tratado mostra características de material ainda biodegradável, sendo provavelmente transformada quando da sua aplicação no solo. O material mais recalcitrante poderá ser incorporado ao húmus, controlando propriedades do solo como a capacidade de troca de cátions, acidez, absorção de água, entre outros.

\section{AGRADECIMENTOS}

Ao Centro Paula Souza (ETEC Astor de Mattos Carvalho), pelo local de instalação e acompanhamento diário do sistema. À Firestone Building do Brasil e à Ecosys, pelo material do biodigestor (Geomembrana de EPDM) e serviço especializado de instalação, bem como à Prefeitura Municipal de Cabrália Paulista pelo serviço de terraplenagem. Lilian Martelli agradece ao IQSC/USP e ao $\mathrm{CNPq}$ pela bolsa de mestrado. Projeto financiado pela Embrapa (MP3 - 03.06.06.014).

\section{REFERÊNCIAS}

1. Cunha, L.; Dissertação de Mestrado, Universidade Federal de Santa Catarina, Brasil, 2007.

2. Castanho, D.; Arruda, H. J.; Resumos da VI Semana de Tecnologia em Alimentos, Ponta Grossa, Brasil, 2008.

3. Sinton, J. E.; Fridley, D. G.; Environ. Pollut. 2000, $28,671$.

4. Martinot, E.; Environ. Pollut. 2001, 29, 581.

5. Kunz, A.; Higarashi, M. M.; Oliveira, P. A.; Matei, R. M.; Miguel, W. C.; Resumos do III Simpósio Gaúcho de Educação Ambiental, Erechim, Brasil, 2004.

6. Ribas, M. M. F.; Barana, A. C.; Sci. Agric. 2003, 60, 223.

7. Amaral, C. M. C.; Amaral, L. A.; Lucas-Júnior, J.; Nascimento, A. A.; Ferreira, D. S.; Machado, M. R. F.; Cienc. Rural 2004, 34, 1897.

8. Souza, C. F.; Lucas-Júnior, J.; Ferreira, W. P. M.; Eng. Agric. 2005, 25, 530.

9. Novaes, A. P.; Simões, M. L.; Martin-Neto, L.; Cruvinel, P. E.; Santana, A.; Novotny, E. H.; Santiago, A.; Nogueira, A. R. A.; Utilização de uma Fossa Séptica Biodigestora para Melhoria do Saneamento Rural e Desenvolvimento da Agricultura Orgânica, Embrapa: São Carlos (Nota Técnica), 2003.

10. Novaes, A. P.; Simões, M. L.; Inamasu, R. Y.; Jesus, E. A. P.; MartinNeto, L.; Santiago, G.; Da Silva, W. T. L. Em Gestão de Resíduos na
Agricultura e Agroindústria; Spadotto, C. A.; Ribeiro, W. C., eds.; FEPAF: Botucatu, 2006, cap. 11.

11. França, C. G.; Del Grossi, M. E.; Marques, V. P. M. A.; O censo agropecuário 2006 e a agricultura familiar no Brasil, MDA: Brasília, 2009.

12. http://www.sidra.ibge.gov.br/bda/pecua/default.asp, acessada em Julho 2011.

13. Melo, W. J.; Marques, M. O.; Santiago, G.; Chelli, R. A.; Leite, S. A. S.; Rev. Bras. Ciênc. Solo 1994, 18, 449.

14. Sousa, J. T.; Leite, V. D.; Luna, J. G.; Rev. Bras. Eng. Agric. Ambiental 2001, 5, 107.

15. Ngole, V.; Mpuchane, S.; Totolo, O.; Eur. J. Soil Biol. 2006, 42, 208.

16. Hussar, G. J.; Paradela, A. L.; Bastos, M. C.; Reis, T. K. B.; Jonas, T. C.; Serra, W.; Gomes, J. P. R.; Eng. Amb. Pesq. Tecnol. 2005, 2, 35.

17. Fonseca, A. F.; Melfi, A. J.; Monteiro, F. A.; Montes, C. R.; Almeida, V. V.; Herpin, U.; Agric. Water Manage. 2007, 87, 328.

18. Fonseca, A. F.; Alleoni, L. R. F. ; Melfi, A. J.; Montes, C. R.; Sci. Agric. $\mathbf{2 0 0 5}, 62,552$.

19. Faustino, A. S.; Dissertação de Mestrado, Universidade Federal de São Carlos, Brasil, 2007.

20. Firme, P. F.; Tese de Doutorado, Universidade de São Paulo, Brasil, 2007.

21. APHA; AWWA; WPCF; Standard methods for the examination of Water and Wastewater, 20 ${ }^{\text {th }}$ ed., American Public Health Association/American Water Works Association/Water Environment Federation: Washington, 1998.

22. Martin-Neto, L.; Milori, D. M. P. B.; Silva, W. T. L.; Simões, M. L. Em Biophysico-Chemical Processes involving natural nonliving organic matter in environmental systems; Senesi, N.; Xing, B.; Houang, P. M., eds.; John Wiley \& Sons: Hoboken, 2009, cap. 16.

23. Santos, L. M.; Simões, M. L.; Da Silva, W. T. L.; Milori, D. M. B. P.; Montes, C. R.; Melfi, A. J.; Martin-Neto, L.; Eclet. Quím. 2009, 34, 39.

24. Zuquette, L. V.; Pejon, O. J.; Gandolfi, N.; Sinelli, O.; Geociências 1993, 12,531 .

25. Conselho Nacional do Meio Ambiente-CONAMA; Resolução n. 357, de 17/3/2005

26. Kunz, A.; Miele, M.; Steinmetz, R. L. R.; Bioresour. Technol. 2009, 100, 5485.

27. Almeida, T. L.; Tese de Doutorado, Universidade de São Paulo, Brasil, 2009. 